\section{Repair of subdivided left atrium associated with persistent left superior vena cava \\ To the Editor:}

We read with interest the communication by Kreutzer and associates" titled "Persistent Left Superior Vena Cava: An Unusual Cause of Subdivided Left Atrium," in which they report on six young children and infants with subdivided left atrium (cor triatriatum), persistent left superior vena cava (SVC), and associated anomalies. In the five patients on whom they operated, the tissue ridge dividing the left atrium into two chambers was excised, the coronary sinus was unroofed, the atrial septal defect was closed with an autologous pericardial patch, and the coronary sinus was closed with continuous suture. The left SVC was divided close to its entrance into the left atrium, and both ends were oversewn; in the two patients in whom an innominate vein was absent, an $8 \mathrm{~mm}$ polytetrafluoroethylene conduit was placed between both SVCs. Although we applaud the applied repair technique for subdivided left atrium with left SVC, we have some concern regarding the construction of a polytetrafluoroethylene conduit between both SVCs, because such a conduit may become obstructed with time. We, and others, favor an extracardiac rerouting of the left SVC by anastomosing the left SVC to the right SVC in an end-to-side fashion, or, in case of absence of the right SVC or the presence of a diminutive right SVC, anastomosing the left SVC to the right atrial appendage. ${ }^{2,3}$

We recently have operated on a 7 -week-old female infant with subdivided left atrium, persistent left SVC (without innominate vein), unroofed coronary sinus, and coronary sinus atrial septal defect. Whereas in unroofed coronary sinus with left SVC we generally favor an extracardiac rerouting of the left SVC, in this specific case we followed a different strategy. At operation, the atrial septum was completely excised except for its inferior rim. At the side of the mitral valve orifice, the diaphragm dividing the left atrium was detached from the left atrial wall over a distance slightly more than 180 degrees of the total circumference (Fig. 1). The orifice in the diaphragm was closed with a small pericardial patch. The flap thus created was augmented with untreated autologous pericardium and, by means of a continuous suture, sewn into place with 5-0 polypropylene (Prolene, Ethicon, Inc., Somerville, N.J.) in such a fashion that all of the puimonary veins drained beneath the patch to the mitral valve orifice. The orifices of the inferior vena cava and both SVCs all then drained on the right side of the patch.

Despite adequate treatment with afterload-reducing agents, the postoperative course was characterized by a high filling pressure (up to $17 \mathrm{~mm} \mathrm{Hg}$ ) in the newly constructed low-compliance left atrial compartment and bouts of supraventricular tachycardia. After 4 days, there was a gradual decrease in the left atrial filling pressure. On the seventh postoperative day, the left atrial filling pressure had decreased to $9 \mathrm{~mm} \mathrm{Hg}$. Echocardiography demonstrated an unobstructed connection from the pulmonary veins to the mitral valve orifice. The patient was discharged after 18 days. At 11-month follow-up, the patient is in excellent clinical condition.

The main advantage of the repair technique as applied in the unique anatomy as present in our patient, as

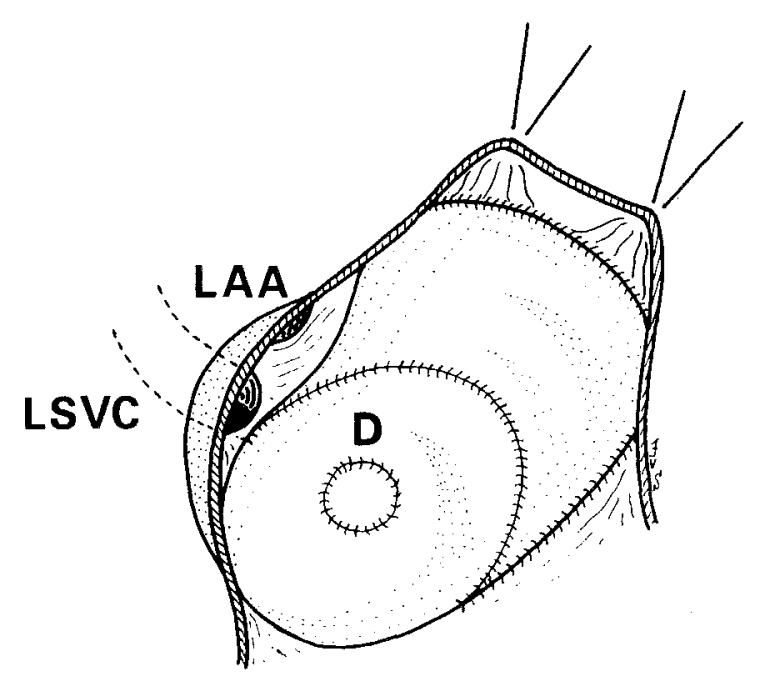

Fig. 1. Repair of divided left atrium associated with unroofed coronary sinus and persistent left superior vena cava $(L S V C)$. Note orifice to left atrial appendage $(L A A)$. After atrial septectomy, toward the mitral valve orifice, the diaphragm $(D)$ between the pulmonary venous chamber and the remainder of the left atrium is partially detached and is augmented with untreated pericardium. The baffle thus constructed is placed to connect the pulmonary veins and the mitral valve orifice. The orifice in the diaphragm is closed with pericardium.

compared with the traditional baffle repair for unroofed coronary sinus, consists of avoidance of a suture line at the superior aspect of the pulmonary veins. In addition, use of the diaphragm offers the potential for growth of the baffle. Both factors may lower the potential risk of pulmonary venous obstruction. A disadvantage of our techniquc consists of the fact that a relatively small and shallow left atrial compartment is created with a low compliance that may negatively affect left ventricular filling.

Jacques A. M. van Son, $M D, P h D$

Jörg Hambsch, $M D$

Departments of Cardiac Surgery and Pediatric Cardiology Herzzentrum

University of Leipzig Russenstrasse 19 D-04289 Leipzig, Germany

\section{REFERENCES}

1. Kreutzer C, Santiago G, Varon RF, Roman MI, Grippo M, Vazquez $\mathrm{H}$, et al. Persistent left superior vena cava: an unusual cause of subdivided left atrium. J Thorac Cardiovasc Surg 1998;115:462-4.

2. Van Son JAM, Hambsch J, Mohr FW. Repair of complex unroofed coronary sinus by anastomosis of left to right superior vena cava. Ann Thorac Surg 1998;65:280-1.

3. Reddy VM, McElhinney DB, Hanley FL. Correction of left superior vena cava draining to the left atrium using extracardiac techniques. Ann Thorac Surg 1997;63:1800-2.

$12 / 8 / 91372$ 